\title{
A Versatile Liquid Culture Method to Control the in Vitro Development of Shoot and Root Apical Meristems of Bamboo Plants
}

\author{
Most Tanziman Ara1, Taiji Nomura², Yasuo Kato², Shinjiro Ogita ${ }^{*}$ \\ ${ }^{1}$ Graduate School of Comprehensive Scientific Research, Prefectural University of Hiroshima, Nanatsukacho, Shobara, \\ Hiroshima, Japan \\ ${ }^{2}$ Biotechnology Research Center and Department of Biotechnology, Toyama Prefectural University, Kurokawa, Imizu, Toyama \\ Japan \\ Email:^ogita@pu-hiroshima.ac.jp
}

How to cite this paper: Ara, M.T., Nomura, T., Kato, Y. and Ogita, S. (2020) A Versatile Liquid Culture Method to Control the in Vitro Development of Shoot and Root Apical Meristems of Bamboo Plants. American Journal of Plant Sciences, 11, 262-275. https://doi.org/10.4236/ajps.2020.112020

Received: January 10, 2020

Accepted: February 25, 2020

Published: February 28, 2020

Copyright (c) 2020 by author(s) and Scientific Research Publishing Inc. This work is licensed under the Creative Commons Attribution International License (CC BY 4.0)

http://creativecommons.org/licenses/by/4.0/

\section{Open Access}

\begin{abstract}
We focus on controlling morphological and histochemical responses of the shoot apical meristem (SAM) and root apical meristem (RAM) of bamboo node by using a simple and versatile liquid culture system. First, nodes of 11 different bamboo species that belong to seven major bamboo genera (Bambusa, Dendrocalamus, Phyllostachys, Tetragonocalamus, Chimonobambusa, Pleioblastus, and Sasa) were cultured using $2 \mathrm{~mL}$ per well of a liquid medium in a 6-well microplate to form a small-scale liquid culture environment (SLCE). The dormant lateral buds of all bamboo nodes resumed expanding and elongating within 7 days in the SLCE. The dormant and active lateral buds were sectioned longitudinally and stained with Sytox green (SG) to monitor mitotic activity and counterstained with safranin (SF) to detect the inward region of the SAM region. Further, mitotic activity was calculated using a digital imaging analysis, which showed an increase of up to 1.2- to 3.8 -fold in terms of the SG/SF ratio after 7 days in the culture. Moreover, we used in vitro node cultures of two typical bamboo species, the sympodial clump-forming type (Bambusa multiplex Raeush, $\mathrm{Bm}$ ) and the monopodial single culm-forming type (Phyllostachys meyeri McClure, Pm), and noted the following: 1) since gradual white-to-green tinge shoots were observed, we investigated the relation between color variation in the outer regions of culm and node tissues and their suitability as explants. By checking the autofluorescence property of whole shoots under LED $365 \mathrm{~nm}$ illumination with an RGB (red, green, and blue) digital imaging analysis using ImageJ software, we specified the color variation of explants as the relative intensity of the blue value. 2) Since the obtained shoots of a 1-month-old culture box showed
\end{abstract}


growth variation, we distinguished shoot types based on plant height, i.e., short (less than $5 \mathrm{~cm}$ ), medium $(\mathrm{ca} .5-10 \mathrm{~cm}$ ), and tall (more than $10 \mathrm{~cm}$ ). Tall shoots that have ca. 5 nodes on average were suitable for explant. 3) Three types of node portions - the first node (the base node near a rhizome tissue), middle nodes (upper nodes near the $1^{\text {st }}$ node), and the top meristem-were independently cultured in the SLCE, and it was found that the first node showed the best growth performance. 4) By culturing the first node in the SLCE system, we performed a quick survey during the 3 weeks in the culture and found that a combination of $10 \mu \mathrm{M}$ benzyl adenine and $3 \mu \mathrm{M}$ thidiazuron was effective for in vitro SAM development, while the addition of 2, 4-D was effective for promoting in vitro RAM development. 5) The detailed autofluorescence properties of the outer regions of culm and node tissues were also identified using an inverted fluorescent microscope under Band U-excitation lights with RGB and HSB (hue, saturation, and brightness) digital imaging analysis.

\section{Keywords}

Bamboo, Digital Imaging, Node Culture, RAM, SAM, SLCE

\section{Introduction}

Bamboo plants that belong to the Poaceae family, which contains more than 1500 species, have been exploited for a range of uses, such as food, medicine, charcoal products, and housing materials, especially in Asia [1] [2]. It is well known that bamboo presents unique biological properties in its vegetative growth. A rhizome system is a key to maintain the lateral growth and form new culms with abundant nodes for longitudinal growth without secondary growth. The system is mainly classified into two types of growth feature: one is the sympodial and the clump-forming type (e.g., Bambusa sp.), which is distributed in tropical regions, and the other is the monopodial and single culm-forming type (e.g., Phyllostachys sp.), which grows mainly in temperate and subtropical regions [3].

A tissue culture protocol of bamboo (Phyllostachys meyeri McClure, Pm) was successfully achieved by Ogita et al. (2008) specifically regarding in vitro germination of the caryopses and plant regeneration from nodal segments of both the germinated seedlings and tissue-cultured clone plants [4]. In vitro node culture stocks of (Bambusa multiplex Raeush, Bm) have also been established using the method for Pm, as previously reported. Hence, several clonal small plantlets of two major bamboo species that have a high ability to form multiple shoots were obtained in a regular period (ca. every 1 - 2 months), as shown in Figure 1. The node portions of these culture stocks with apical and intercalary meristems were considered as excellent models for the morphological and histochemical response control of the shoot apical meristem (SAM) and root apical meristem 

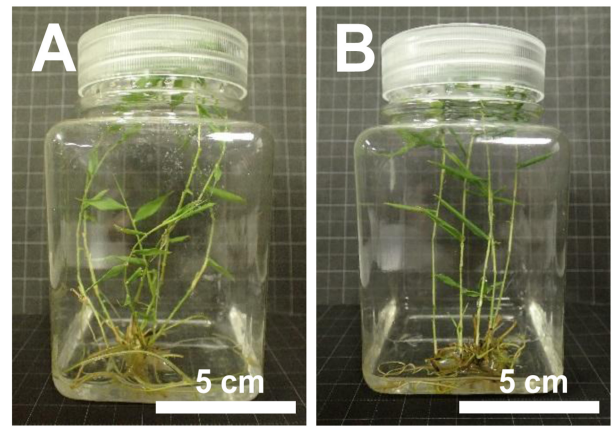

Figure 1. The features of in vitro node culture stocks of (A): Bambusa multiplex Raeush, Bm; and (B): Phyllostachys meyeri McClure, Pm.

(RAM) of bamboo. General tissue culture techniques for in vitro micropropagation of bamboos through enhanced axillary branching using node explants have been well reviewed, e.g. by Singh et al. (2013) [5]. Factors affecting success in micropropagation of bamboos such as medium, plant growth regulators, medium $\mathrm{pH}$, carbon source, propagule size, and culture duration were summarized in this report. However, there is no detailed description of a versatile methodology to regulate in vitro growth of bamboo nodes. The aim of this study is to review a simple but versatile node culture system in a liquid culture environment to better understand unique biological properties of its vegetative growth and to, thus, reveal the relation between color variation in the outward regions of culm and node tissues and their suitability as explants.

The concept of the Plan-Do-Check-Act (PDCA) cycle in a plant tissue culture [6] is central for the present study. Generally, researchers should realistically consider the following requirements: explant selection, medium preparation, and culture environment setting in the $\mathrm{P}$ and $\mathrm{D}$ cycles. Based on a careful monitoring of size, shape, and color variation of the target cells and tissues by macroand micro-scopic observations, they can recognize the specific pattern of growth promotion and/or inhibition during the culture of the target explant. These inputs are considered highly useful and interesting for the optimization of a protocol, especially regarding the $\mathrm{C}$ and $\mathrm{A}$ cycles.

A main topic of the present study is the culture environment setting. Sood et al. (2002) tested the effects of agar-solidified medium and liquid medium on shoot multiplication, whereby root formation of Dendrocalamus hamiltonii was investigated; it was found that a liquid culture condition is more suitable for the tissue culture of this bamboo species [7]. Using node culture system, we checked the effects of solid and liquid media on the growth of bamboo node cultures of $\mathrm{Bm}$ and $\mathrm{Pm}$, and found that better growth performance was observed in the liquid medium condition (Table 1). Based on this preliminary result, a 6-well microplate that contains $2 \mathrm{~mL}$ per well of a liquid medium, which provides a small-scale liquid culture environment (SLCE) for optimizing the culture protocol of the bamboo within a short period was focused in the present study. 
Table 1. Effect of solid and liquid medium conditions on growth performance of bamboo node cultures.

\begin{tabular}{cccccc}
\hline \multirow{2}{*}{$\begin{array}{c}\text { Species/ } \\
\text { medium } \\
\text { condition }\end{array}$} & $\begin{array}{c}\text { Plant height } \\
(\mathrm{cm})\end{array}$ & $\begin{array}{c}\text { No of } \\
\text { shoots/ } \\
\text { explant }\end{array}$ & $\begin{array}{c}\text { No. of roots/ } \\
\text { explant }\end{array}$ & $\begin{array}{c}\text { Length of } \\
\text { root } \\
(\mathrm{cm})\end{array}$ & $\begin{array}{c}\text { Weight } \\
\text { incensement } \\
(\mathrm{mg})\end{array}$ \\
\hline Bm/Solid & $4.22 \pm 0.95$ & $1.2 \pm 0.12$ & $1.4 \pm 0.47$ & $5.84 \pm 1.11$ & $96 \pm 0.03$ \\
Bm/Liquid & $9.9 \pm 1.16$ & $1.2 \pm 0.15$ & $4.6 \pm 0.59$ & $8.26 \pm 1.39$ & $338 \pm 0.04$ \\
p-value & $0.00139^{* *}$ & 0.5 & $0.011866^{* *}$ & 0.165642 & $0.003522^{* *}$ \\
Pm/Solid & $4.95 \pm 1.17$ & $1 \pm 0.21$ & $2.1 \pm 0.45$ & $2.1 \pm 1.19$ & $44 \pm 0.42$ \\
Pm/Liquid & $7.6 \pm 3.00$ & $1.6 \pm 0.40$ & $2.4 \pm 0.75$ & $8 \pm 1.27$ & $191 \pm 0.38$ \\
p-value & 0.216171 & 0.086002 & 0.85559 & $0.044966^{* *}$ & $0.011815^{* *}$ \\
\hline
\end{tabular}

Growth performance was summarized after 30 days in culture. Data represent the average values \pm SD from 5 explants. Data for each column were analyzed by a Student's t-test. ${ }^{* *}$ Significant at 0.05 .

Another main topic of the present study is the autofluorescence measurement technique. Autofluorescence (primary fluorescence) is the fluorescence of naturally occurring substances, such as chlorophyll, collagen, and fluorite. Most plant and animal tissues show some autofluorescence when excited with ultraviolet light (e.g., light with a wavelength of approximately $365 \mathrm{~nm}$ ) [8]. In the previous studies, we focused on evaluating the autofluorescence intensity of target plant cells, which reflects the histochemical features of the plant cell wall [9], and accumulation of specific secondary metabolites [10]. We also used digital imaging analysis to measure the growth features in a protoplast co-culture assay [11]. Currently, in the field of life sciences, the concept and application of autofluorescence measurement have developed with the requirement of non-destructive detection of a target cell and tissue [12] [13] [14]. In the present study, the color variation of explants as the relative fluorescent intensity by assessing the autofluorescence property of the whole shoots under LED $365 \mathrm{~nm}$ illumination with RGB (red, green, and blue) digital imaging analysis using ImageJ software was focused. The detailed autofluorescence properties of the outward regions of culm and node tissues were also identified using an inverted fluorescent microscope under B- and U-excitation lights with RGB and HSB (hue, saturation, and brightness) digital imaging analysis.

\section{Materials and Methods}

\subsection{Plant Materials}

Nodes of 11 different bamboo species that belong to seven major bamboo genera were cultivated using planter boxes in a greenhouse of Toyama Prefectural University, Japan: Bambusa-B. multiplex Raeush (Bm), B. glaucescens f. Horaikomachi (Bg), B. oldhamii Munro (Bo); Dendrocalamus-D. giganteus Munro (Dg); Phyllostachys-P. bambusoides Sied. Et Zucc (Pb), P. nigra Munro var. Henonis (Pn), P. pubescens Mazel ex J. Houz (Pp); Tetragonocalamus-T. 
angulatus (Munro) Nakai (Ta); Chimonobambusa-C. marmorea (Mitford) Makino (Cm); Pleioblastus-P. simonii (Carriere) Nakai (Ps); and Sasa-S. kurilensis Makino et Shibata (Sk). Fresh nodes were collected from the branches of these bamboo plants and cultured in vitro according to a method previously reported [4]. In vitro node culture stocks of $\mathrm{Bm}$ and $\mathrm{Pm}$ maintaining at Prefectural University of Hiroshima, Japan were also used in the following experiments to understand the sequential developmental processes of SAM and RAM of node explants. Briefly, a half-strength MS (Murashige and Skoog) [15] liquid medium that contains $30 \mathrm{~g} / \mathrm{L}$ sucrose was prepared as a standard medium, unless otherwise specified. The $\mathrm{pH}$ of the medium was adjusted to 5.7 before autoclaving. All the cultures were maintained at $25^{\circ} \mathrm{C}$, with a $16 \mathrm{~h}$ photoperiod under fluorescent illumination $\left(65 \mu \mathrm{mol} \mathrm{m}^{-2} \mathrm{~s}^{-1}\right)$.

\subsection{Node Culture Protocol and Its Applications}

A versatile node culture protocol using $2 \mathrm{~mL}$ per well of a liquid half-strength MS medium with a 6-well microplate (\#353046, Corning), which provided a small-scale liquid culture environment (SLCE) was demonstrated. One node segment (1.5 $-2.0 \mathrm{~cm}$ in length) of each bamboo plant was placed in a well of the SLCE. Mature dormant nodes from greenhouse grown bamboo branches and the first node (the base node near a rhizome tissue) from the in vitro node cultures of Pm and $\mathrm{Bm}$ were used in the experiments, unless otherwise specified.

Three types of node portions - the first node, middle nodes (upper nodes next to the 1st node), and the top meristem-were independently cultured in the SLCE to define a bent for the explants. Effects of plant growth regulators, such as benzyl adenine (BA, Wako Pure Chemical Corp.) and thidiazuron (TDZ, Wako Pure Chemical Corp.), on induction of in vitro SAM development, and effects of 2,4-dichlorophenoxy acetic acid (2,4-D, Wako Pure Chemical Corp.) on the promotion of in vitro RAM development were also investigated after a short period in the SLCE.

\subsection{Observations and Digital Imaging Analysis}

Dormant and active lateral buds of 11 bamboo species were sectioned longitudinally and stained with Sytox green (SG, Thermo Fisher Scientific) to monitor mitotic activity and counterstained with Safranin O (SF, Wako Pure Chemical Corp.) to detect the inward region of the SAM region based on a previous method [16] with a minor modification.

In order to evaluate growth performance of explants, whole images of in vitro cultured shoots were captured with a digital camera system (UV CUBE, LC science Co., Ltd.) under a bright-field and LED $365 \mathrm{~nm}$ illumination without staining. The autofluorescence property of the obtained images was evaluated by RGB (red, green, and blue) digital imaging analysis using ImageJ software. A stereo microscope (SZ40, Olympus) was also used to monitor the morphological characteristics of the target tissue. The detailed autofluorescence properties of 
the outward regions of culm and node tissues were observed using an inverted cell culture microscope (CKX53, Olympus) under B- and U-excitation lights [B; Band pass (BP) filter, 460 - 495; Barrier (BA) filter, 510IF; Dichroic mirror (DM), 505, U-FUW; BP filter, 340 - 390; BA filter, 420IF; DM, 410] with RGB and HSB (hue, saturation, and brightness) digital imaging analysis. The HSB color space in ImageJ software is regarded as equivalent to the HSV (hue, saturation, and value) color space.

\section{Results}

\subsection{Histochemical Analysis of Mitotic Activity in Node Portions of 11 Bamboo Species}

As shown in Figure 2, the dormant lateral buds of all bamboo nodes resumed expansion and elongation within the first 7 days in the SLCE. The mitotic activity was calculated by a digital imaging analysis and found an increase of up to 1.2- to 3.8-fold in terms of the SG/SF ratio after 7 days in the culture (Table 2).
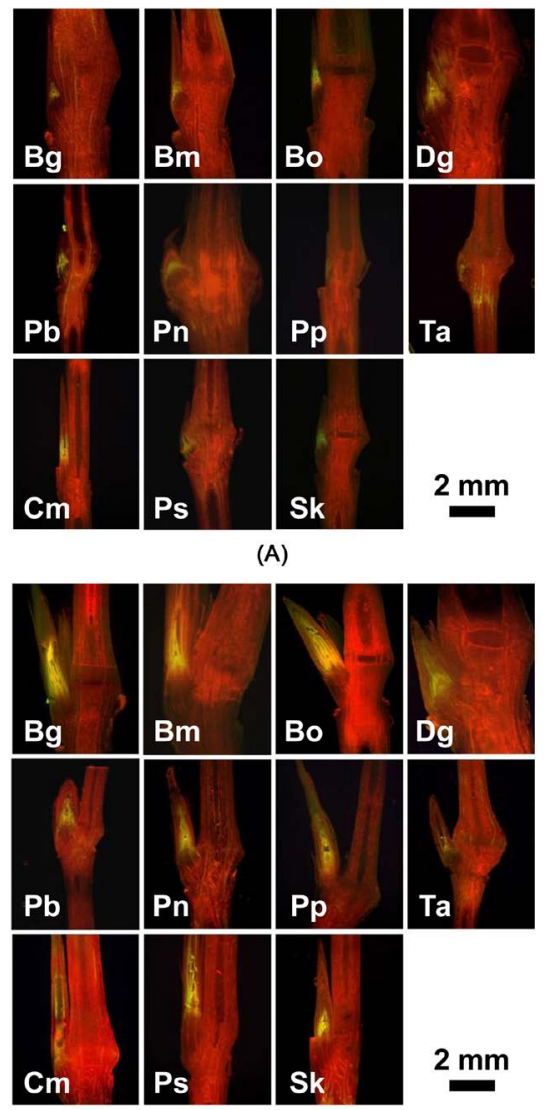

(B)

Figure 2. Histochemical analysis of mitotic activity in node portions of 11 bamboo species. A; dormant stage (0 day), B; active stage (7 days). Longitudinal sections of the lateral buds were stained with Sytox green (SG, yellow) and counter stained with Safranin (SF, red). Relative activity was calculated as the ratio of stained area (SG/SF) in Table 2. 
Table 2. The mitotic activity in the node portion of 11 bamboo species.

\begin{tabular}{cccc}
\hline \multirow{2}{*}{ Bamboo species } & \multicolumn{3}{c}{ Relative activity (SG/Saf) } \\
\cline { 2 - 4 } & Dormant stage & Active stage & Fold \\
\hline $\mathrm{Bg}$ & 0.069 & 0.084 & 1.22 \\
$\mathrm{Bm}$ & 0.058 & 0.083 & 1.45 \\
$\mathrm{Bo}$ & 0.079 & 0.133 & 1.68 \\
$\mathrm{Dg}$ & 0.040 & 0.062 & 1.57 \\
$\mathrm{~Pb}$ & 0.037 & 0.069 & 1.86 \\
$\mathrm{Pn}$ & 0.036 & 0.059 & 1.63 \\
$\mathrm{Pp}$ & 0.050 & 0.109 & 2.17 \\
$\mathrm{Ta}$ & 0.007 & 0.025 & 3.82 \\
$\mathrm{Cm}$ & 0.040 & 0.064 & 1.59 \\
$\mathrm{Ps}$ & 0.068 & 0.098 & 1.44 \\
$\mathrm{Sk}$ & 0.032 & 0.056 & 1.75 \\
\hline
\end{tabular}

${ }^{*}$ Relative activity was calculated as the ratio of stained area (SG/Saf) from Figure 2 by a digital imaging analysis.

\subsection{Morphological Features of in Vitro Bamboo Shoots}

Systematically maintained in vitro node culture stocks of $\mathrm{Bm}$ and $\mathrm{Pm}$, as shown in Figure 1, were used in this experiment. Since gradual white-to-green tinge shoots were observed, we investigated the relation between color variation in the outward regions of culm and node tissues and their suitability as explants (Figure 3). Color variation from pearl to light green under a white light could be observed, which is especially dependent on the position of the internode in the young shoot of Pn. On the other hand, there were no distinctive visible characteristics of the outward regions of the in vitro shoot of $\mathrm{Pm}$ and $\mathrm{Bm}$ under a white light. By checking the autofluorescence property of whole shoots under LED 365 $\mathrm{nm}$ illumination with RGB digital imaging analysis using ImageJ software, the color variation of explants as the relative intensity of the blue value was specified. To refer to a color scale, positional differences of the relative autofluorescence intensity were also identified.

\subsection{Growth Performance of in Vitro Bamboo Shoots}

As shown in Figure 4, we could distinguish types of shoots according to the plant height, i.e., short (less than $5 \mathrm{~cm}$ ), medium (ca. $5-10 \mathrm{~cm}$ ), and tall (more than $10 \mathrm{~cm}$ )-specifically from a culture box of in vitro node culture stock. The number of nodes per shoot varied depending on the size of the shoots. Tall shoots that have ca. 5 nodes on average are suitable as explants.

Three types of node portions-the first node, middle nodes, and the top meristem-were collected from tall shoots that were more than $\mathrm{ca} .10 \mathrm{~cm}$ in height and independently cultured in the SLCE to define a bent for the explants. The first node showed better growth performance in terms of weight increment (Figure 5). Further growth features of each node were also monitored (data not 


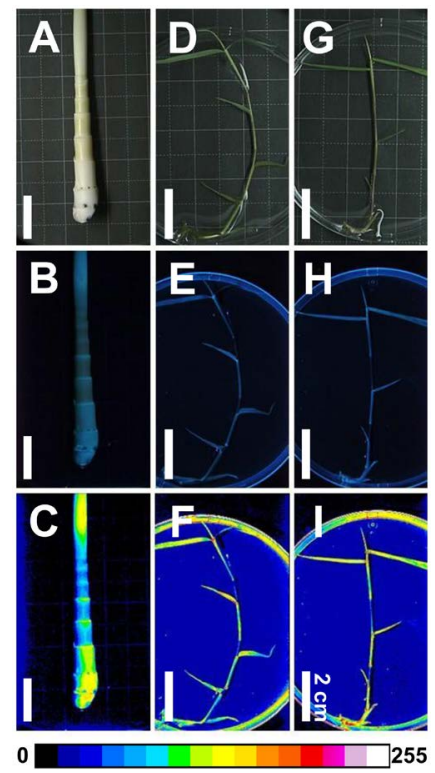

Figure 3. Autofluorescence of whole shoots under LED $365 \mathrm{~nm}$ illumination with an RGB (red, green, and blue) digital imaging analysis. Young shoot of Pn (A)-(C), in vitro shoot of Pm (D)-(F), in vitro shoot of $\mathrm{Bm}(\mathrm{G})-(\mathrm{I})$. Images in (A), (D), and (G) were captured under a white light. (B), (E), and $(\mathrm{H})$ are autofluorescence images. $(\mathrm{C}),(\mathrm{F})$, and $(\mathrm{I})$ are examples of digital imaging analyses in blue mode indicating histochemical differences in the outward regions of the tissues.

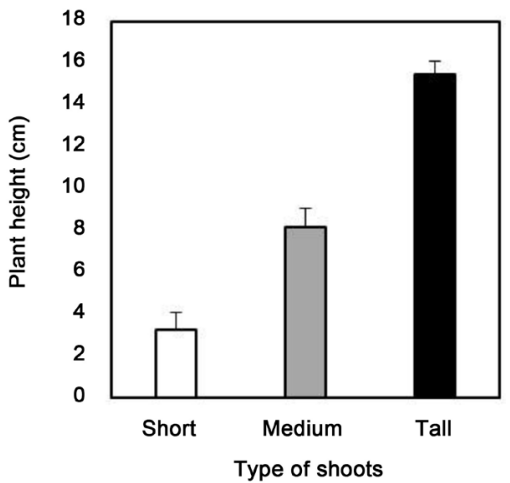

(A)

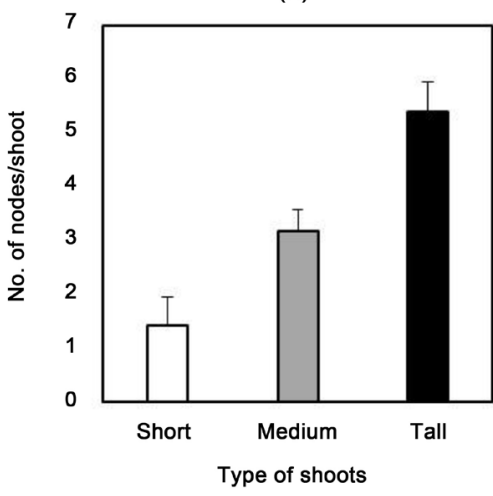

(B)

Figure 4. Categorization of the in vitro Pm shoot types according to (A) plant height, and (B) number of nodes per shoot. Values were summarized after being cultured for 30 days. Data represent the average values \pm SD from 5 independent stock cultures. 


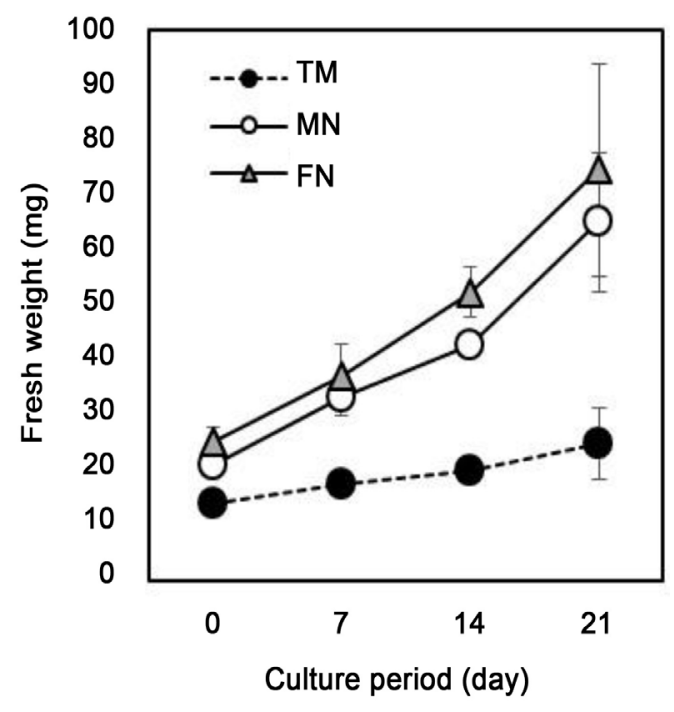

Figure 5. Growth performance of first node (FN), medium node $(\mathrm{MN})$, and top meristem (TM). Data represent the average values \pm SD from 3 explants.

shown) and it was concluded that the first nodes have superior bent for explants of the bamboo node culture. By selecting the first nodes as suitable explants, a quick survey to set a highly efficient culture condition became theoretically possible.

Without selecting the best node tissues, i.e., first nodes, the resulting responses of a culture tend to vary widely. We effectively reconfirmed the superior bent of the first node when a test survey that set a highly efficient culture condition was performed as follows. Different concentrations and a combination of cytokinins, i.e., $3 \mu \mathrm{M}$ of $\mathrm{TDZ}$, and 3 and $10 \mu \mathrm{M}$ of $\mathrm{BA}$, were used for in vitro SAM development, and different concentrations of auxin, i.e., $0.1,3$, and $10 \mu \mathrm{M}$ of 2,4-D, were also evaluated for whether in vitro RAM development was promoted. As expected, clear growth promotion and/or inhibition could be seen in the SLCE, especially in terms of the day to bud break values (Table 3 ).

\subsection{Autofluorescence Properties of the Outward Regions of Culm and Node Tissues}

Given the relation between color variation in the outward regions of culms and nodes and their suitability as explants (see Figure 3), we attempted to identify the detailed autofluorescence properties of the target tissues using an inverted fluorescent microscope under B- and U-excitation lights with an RGB and HSB digital imaging analysis. As shown in Figure 6, the mature node region, especially near the first node, showed various strong fluorescence intensities. When B-excitation light was adapted, the images from the R and G modes of the RGB analysis and the hue and brightness modes of the HSB analysis were estimable. When $U$-excitation light was used, the images from the $G$ and $B$ modes of the RGB analysis and the brightness mode of the HSB analysis were visible. 
Table 3. Effect of plant growth regulators on shoot/root/callus development from first node explants.

\begin{tabular}{|c|c|c|c|}
\hline \multirow{2}{*}{$\begin{array}{l}\text { Plant growth } \\
\text { regulator }(\mu \mathrm{M})\end{array}$} & \multicolumn{3}{|c|}{ Growth performance } \\
\hline & $\begin{array}{l}\text { Days to bud } \\
\text { breaking }(\mathrm{d})\end{array}$ & $\begin{array}{l}\text { Length of } \\
\text { shoot }(\mathrm{cm})\end{array}$ & Shoot/root/callus development \\
\hline 0 & $15.8 \pm 2.34$ & $4.1 \pm 0.31$ & Single shoot elongation (control) \\
\hline TDZ 3 & $8.00 \pm 0.84$ & $2.9 \pm 0.32$ & $\begin{array}{l}\text { Single shoot elongation with moderate } \\
\text { inhibition }\end{array}$ \\
\hline BA 3 & $5.5 \pm 0.55$ & $6.7 \pm 0.22$ & $\begin{array}{l}\text { Single shoot elongation with active } \\
\text { promotion }\end{array}$ \\
\hline BA 10 & $4.3 \pm 0.55$ & $7.1 \pm 4.33$ & $\begin{array}{l}\text { Single shoot elongation with active } \\
\text { promotion }\end{array}$ \\
\hline $\mathrm{BA} 10+\mathrm{TDZ} 3$ & $3.00 \pm 0.45$ & $2.8 \pm 0.26$ & $\begin{array}{l}\text { Multiple shoots elongation with } \\
\text { moderate inhibition }\end{array}$ \\
\hline 2,4-D 0.1 & $7.8 \pm 0.82$ & $4.4 \pm 0.16$ & $\begin{array}{l}\text { Single shoot elongation same as control } \\
\text { with single root elongation }\end{array}$ \\
\hline 2,4-D 3 & $11.17 \pm 0.89$ & $3.8 \pm 0.08$ & $\begin{array}{l}\text { Single shoot elongation and slight } \\
\text { callusing at the base of the node tissue }\end{array}$ \\
\hline 2,4-D 10 & $1.8 \pm 3.03$ & $0.15 \pm 0.25$ & $\begin{array}{l}\text { Moderate callusing at joint region of } \\
\text { node tissue }\end{array}$ \\
\hline
\end{tabular}

Growth performances were summarized after cultured for 21 days. Data represent the average value \pm SD from 5 explants.

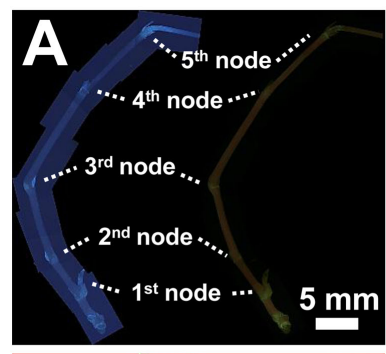

\section{RGB imaging analysis}

(1) File>Open (Select a RGB color picture such as “.jpg"),

(2) Image $>$ Type $>$ RGB stack (Sprit the image into 8-bit grays),

(3) Image >Lookup tables >Spectrum (Red in B, Green in C, Blue in D).

\section{HSB imaging analysis}

(1) File>Open (Select a RGB color picture such as ".jpg"),

(2) Image $>$ Type $>$ HSB stack (Sprit the image into 8-bit grays),

(3) Image >Lookup tables >Spectrum (Hue in E, Saturation in F, Brightness in G).
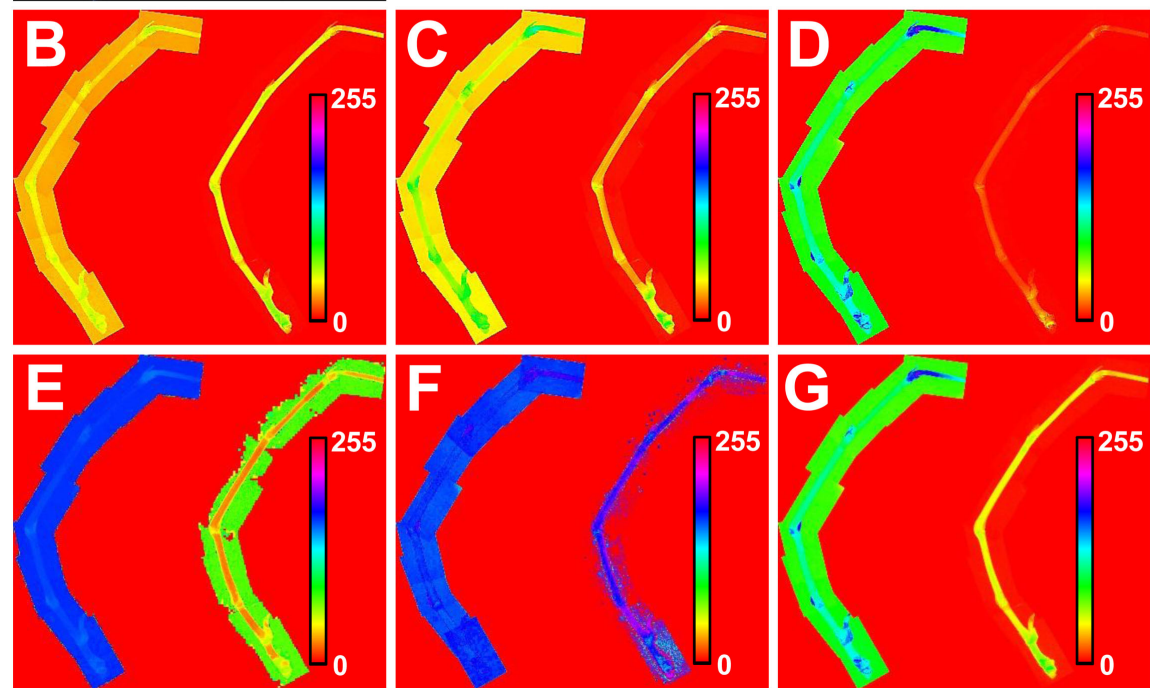

Figure 6. Autofluorescence of the outward regions of the tissues of culms and nodes under B- and U-excitation lights with an RGB and HSB (hue, saturation, and brightness) digital imaging analysis. 


\section{Discussion}

A liquid medium condition has previously been suggested to be suitable for in vitro bamboo tissue cultures, especially in three major bamboo genera (Bambusa, Dendrocalamus, Phyllostachys) [4] [7] [17] [18]. In the present study, we investigated the effects of solid and liquid media on the growth of bamboo node cultures of $\mathrm{Bm}$ and $\mathrm{Pm}$, and found that better growth performance could be observed in the liquid medium condition (see Table 1 ). Then, we focused on using a 6-well microplate that contains $2 \mathrm{~mL}$ per well of a liquid medium, which provides a small-scale liquid culture environment (SLCE). The underlying concepts of the SLCE are as follows: 1 ) to establish a simple and versatile liquid assay system to control morphological and histochemical responses of SAM and RAM of the bamboo node within a short period, and 2) to reveal the relation between color variation in the outward regions of culm and node tissues and their suitability as explants using techniques for autofluorescence measurement with a digital imaging analysis. For the first concept, we evaluated growth performance of nodes from 11 different bamboo species that belong to seven major bamboo genera (Bambusa, Dendrocalamus, Phyllostachys, Tetragonocalamus, Chimonobambusa, Pleioblastus, and Sasa), and concluded that the first node is the best explant for the bamboo culture system. As a test assay, we investigated the effects of plant growth regulators-both auxin and cytokinin-since it is well known that these chemicals interact in a complex manner to control many aspects of growth and differentiation [19]. The auxin-cytokinin interaction in the regulation of plant meristem development is overviewed in terms of biosynthesis, transport, and signaling control [20]. As shown in Table 3, we recognized that the combination of $10 \mu \mathrm{M}$ of $\mathrm{BA}$ and $3 \mu \mathrm{M}$ of TDZ was effective for in vitro SAM development during 3 weeks of culture. The addition of TDZ served as a trigger to induce multiple shoots. There are reports that TDZ is effective for enhancing micropropagation in cereal and grass plants [21] [22]. Moreover, the addition of 2,4-D effectively promoted in vitro RAM development. Interestingly, it was capable to monitor different bud breaking patterns ( 2 - 10 days after culture) with various RAM developments through the test assay. The low concentration of $0.1 \mu \mathrm{M}$ was effective for shoot and root development, while the high concentration of $10 \mu \mathrm{M}$ induced early bud breaking with callusing.

For the second concept, using macro- and microscopic fluorescence observation techniques, as described in the text, we estimated autofluorescence properties in the outward regions of bamboo node tissues by performing an RGB and HSB digital imaging analysis. The color of an object can be described by several color coordinate systems, referred to as color spaces. One of the most important decisions for imaging analysis is to select a color space, of which the most popular is RGB, often used in video monitors. HSV (HSB in ImageJ) is an alternative representation of the RGB color model designed to be more closely aligned to human vision and perception of color-making attributes [23]. As shown in Figure 6, we compared all the images obtained, and decided a suitable combination 
of B- and U-excitation lights with an RGB and HSB digital imaging analysis.

\section{Conclusion}

To the best knowledge, this is the first report that suggests a versatile node culture method in the SLCE to control morphological and histochemical responses of SAM and RAM in in vitro bamboo plants. Clear growth promotion and/or inhibition could be seen in the SLCE within a short period. For future studies, we are constructing detailed quantitative imaging analyses on the variation of the autofluorescence property by adapting a method [24] with our new culture system.

\section{Acknowledgements}

This study was supported in part by Grants-in-Aid for Scientific Research (C) (Grant No. 22580387 and 25450519 to S.O.) from the Japan Society for the Promotion of Science (JSPS). The author (M.T.A.) thanks to the Rotary Yoneyama Memorial Foundation, Japan Student Services Organization (JASSO), Hiroshima International Centre (HIC) and Daikyo Nishikawa Company Ltd., JAPAN for providing the scholarships to finalize this research work.

\section{Conflicts of Interest}

The authors declare no conflicts of interest regarding the publication of this paper.

\section{References}

[1] Bystriakova, N., Kapos, V., Stapleton, C. and Lysenko, I. (2003) Bamboo Biodiversity: Information for Planning Conservation and Management in the Asia-Pacific Region. UNEP-WCMC/INBAR 1, Cambridge, 1-72.

https://archive.org/details/bamboobiodiversi03byst

[2] Clark, L.G., Londono, X. and Ruiz-Sanchez, E. (2015) Bamboo Taxonomy and Habitat. In: Liese, W. and Köhl, M., Eds., Bamboo: The Plant and Its Uses, Springer, Berlin, 1-30. https://doi.org/10.1007/978-3-319-14133-6

[3] Ohrnberger, D. (1999) The Bamboos of the World: Annotated Nomenclature and Literature of the Species and the Higher and Lower Taxa. Elsevier, Amsterdam, 596. https://doi.org/10.1016/B978-0-444-50020-5.X5000-X

[4] Ogita, S., Kashiwagi, H. and Kato, Y. (2008) In Vitro Node Culture of Seedlings in Bamboo Plant, Phyllostachys meyeri McClure. Plant Biotechnology, 25, 381-385. https://doi.org/10.5511/plantbiotechnology.25.381

[5] Singh, S.R., Singh, R., Kalia, S., Dalal, S., Dhawan, A.K. and Kalia, R.K. (2013) Limitations, Progress and Prospects of Application of Biotechnological Tools in Improvement of Bamboo-A Plant with Extraordinary Qualities. Physiology and Molecular Biology of Plants, 19, 21-41. https://doi.org/10.1007/s12298-012-0147-1

[6] Ogita, S. (2015) Plant Cell, Tissue and Organ Culture: The Most Flexible Foundations for Plant Metabolic Engineering Applications. Natural Product Communications, 10, 815-820. https://doi.org/10.1177/1934578X1501000527

[7] Sood, A., Ahuja, P.S., Sharma, O.P. and Godbole, S. (2002) In Vitro Protocols and 
Field Performance of Elites of an Important Bamboo Dendrocalmus hamiltonii Nees et Arn. Ex Munro. Plant Cell Tissue and Organ Culture, 71, 55-63. https://doi.org/10.1023/A:1016582732531

[8] Rost, F. (1999) Fluorescence Microscopy, Applications. In: Lindon, J.C., Ed., Encyclopedia of Spectroscopy and Spectrometry, Academic Press, Cambridge, 565-570. https://doi.org/10.1006/rwsp.2000.0090

[9] Ogita, S., Kikuchi, N., Nomura, T. and Kato, Y. (2011) A Practical Protocol for Particle Bombardment-Mediated Transformation of Phyllostachys Bamboo Suspension Cells. Plant Biotechnology, 28, 43-50. https://doi.org/10.5511/plantbiotechnology.10.1101a

[10] Ogita, S., Lee, J.B., Kurosaki, F. and Kato, Y. (2015) The Biosynthetic Activities of Primary and Secondary Metabolites in Suspension Cultures of Aquilaria microcarpa. Natural Product Communications, 10, 779-782.

https://doi.org/10.1177/1934578X1501000520

[11] Ogita, S. and Sasamoto, H. (2017) In Vitro Bioassay of Allelopathy in Four Bamboo Species; Bambusa multiplex, Phyllostachys bambusoides, P. nigra, Sasa kurilensis, Using Sandwich Method and Protoplast Co-Culture Method with Digital Image Analysis. American Journal of Plant Sciences, 8, 1699-1710.

https://doi.org/10.4236/ajps.2017.87117

[12] Croce, A.C. and Bottiroli, G. (2014) Autofluorescence Spectroscopy and Imaging: A Tool for Biomedical Research and Diagnosis. European Journal of Histochemistry, 58, 2461. https://doi.org/10.4081/ejh.2014.2461

[13] Zheng, X., Xiong, H., Li, Y., Han, B. and Sun, J. (2016) RGB and HSV Quantitative Analysis of Autofluorescence Bronchoscopy Used for Characterization and Identification of Bronchopulmonary Cancer. Cancer Medicine, 5, 3023-3030. https://doi.org/10.1002/cam4.831

[14] Wena, Z., Raffaelloa, T., Zenga, Z., Pavicica, M. and Asiegbua, F.O. (2019) Chlorophyll Fluorescence Imaging for Monitoring Effects of Heterobasidion parviporum Small Secreted Protein Induced Cell Death and in Planta Defense Gene Expression. Fungal Genetics and Biology, 126, 37-49. https://doi.org/10.1016/j.fgb.2019.02.003

[15] Murashige, T. and Skoog, F. (1962) A Revised Medium for Rapid Growth and Bioassays with Tobacco Tissue Cultures. Physiologia Plantarum, 15, 473-497. https://doi.org/10.1111/j.1399-3054.1962.tb08052.x

[16] Ogita, S., Nomura, T., Kishimoto, T. and Kato, Y. (2012) A Novel Xylogenic Suspension Culture Model for Exploring Lignification in Phyllostachys Bamboo. Plant Methods, 8, Article No. 40. https://doi.org/10.1186/1746-4811-8-40

[17] Das, M. and Pal, A. (2005) In Vitro Regeneration of Bambusa balcooa Roxb.: Factors Affecting Changes of Morphogenetic Competence in the Axillary Buds. Plant Cell Tissue and Organ Culture, 81, 109-112. https://doi.org/10.1007/s11240-004-3017-x

[18] Negi, D. and Saxena, S. (2011) Micropropagation of Bambusa balcooa Roxb. through Axillary Shoot Proliferation. In Vitro Cellular and Developmental Biology Plant, 47, 604-610. https://doi.org/10.1007/s11627-011-9403-2

[19] Coenen, C. and Lomax, T.L. (1997) Auxin-Cytokinin Interactions in Higher Plants: Old Problems and New Tools. Trends in Plant Science, 2, 351-356. https://doi.org/10.1016/S1360-1385(97)84623-7

[20] Su, Y.H., Liu, Y.B. and Zhang, X.S. (2011) Auxin-Cytokinin Interaction Regulates Meristem Development. Molecular Plant, 4, 616-625.

https://doi.org/10.1093/mp/ssr007 
[21] Kumari, K., Lal, M. and Saxena, S. (2017) Enhanced Micropropagation and Tiller Formation in Sugarcane through Pretreatment of Explants with Thidiazuron (TDZ). 3 Biotech, 7, 282. https://doi.org/10.1007/s13205-017-0910-7

[22] Schulze, J. (2007) Improvements in Cereal Tissue Culture by Thidiazuron: A Review. Fruit, Vegetable and Cereal Science and Biotechnology, 1, 64-79. http://www.globalsciencebooks.info/Online/GSBOnline/images/0712/FVCSB_1(2)/ FVCSB_1(2)64-79o.pdf

[23] Lazaro, A., Boada, M., Villarino, R. and Girbau, D. (2019) Color Measurement and Analysis of Fruit with a Battery-Less NFC Sensor. Sensors, 19, 1741. https://doi.org/10.3390/s19071741

[24] Kasajima, I. (2019) Measuring Plant Colors. Plant Biotechnology, 36, 63-75. https://doi.org/10.5511/plantbiotechnology.19.0322a 